\title{
Suicide Among Regular-Duty Military Personnel: A Retrospective Case-Control Study of Occupation- Specific Risk Factors for Workplace Suicide
}

\author{
Martin J. Mahon, M.B., M.Sc., \\ M.R.C.Psych.
}

John P. Tobin, M.B., M.R.C.Psych.

Denis A. Cusack, F.R.C.P.I., F.C.I.Arb., B.L.

Cecily Kelleher, F.R.C.P.I., M.D., M.F.P.H.M.

Kevin M. Malone, M.D., F.R.C.P.I., M.R.C.Psych.
Objective: The purpose of this study was to examine the epidemiology, phenomenology, and occupation-specific risk factors for suicide among regular-duty military personnel as a model for other professions at risk for workplace suicide.

Method: Suicide incidence and methods were determined in a retrospective military cohort comprising all deaths $(\mathrm{N}=732)$ of regular-duty military personnel in the Irish Defence Forces between 1970 and 2002. A retrospective, case-control study using pair-matched military comparison subjects was conducted to determine occupation-specific risk factors for suicide, particularly by firearm, among military personnel. Risk factors were subjected to chi-square analysis or independent t tests and entered into a binary logistic regression analysis model.

Results: The period-averaged suicide rate for the cohort was $15.3 / 100,000$. Firearm suicides accounted for $53 \%$ of the cases. Suicides that took place on duty occurred predominantly when personnel were alone shortly after duty commencement in the morning. Bivariate and logistic regression analyses identified psychiatric illness and a past history of deliberate selfharm, morning duty (shortly after duty assumption and consequent access to firearms), and a recent medical downgrading as independent risk factors predicting firearm suicide among military personnel.

Conclusions: Occupation influences suicide method. Access to and opportunity to use lethal means in the workplace are distinct but related occupation-specific suicide risk factors in the military and in other at-risk professions. In professions where access to lethal means is inevitable, moderating opportunity for suicide is crucially important. In regular-duty military personnel, a medical downgrading, combined with risk factors established in civilians such as younger age, male gender, psychiatric illness, and past self-harm, increases the risk of suicide. The findings may be used to guide military harm-reduction strategies and have applicability in strategies for other professions at risk for workplace suicide.

(Am J Psychiatry 2005; 162:1688-1696)

S

uicide is the second most common cause of death in United States military (1) and accounted for substantial mortality in the Russian military (2), among British veterans of the Falkland Islands war (3), and in the recent Iraq conflict (4). The devastating effect of suicides on unit morale should compel research to guide military authorities in the heretofore little explored areas of suicide risk prediction, management, and reduction. Like other employers, military installations are expected to maintain safe work environments that support employees' health. Existing research comprises studies of suicide rates, typically over brief periods of time (see Table 1), and few studies have reliably examined suicide methods or method-specific predictive factors that are particularly relevant for military authorities. Lower suicide rates might be expected in the military, compared to individuals of similar age in the general population, because of the "healthy worker effect" (19), pre-enlistment selection or screening, and the structured, supportive, often interrelated occupational and so- cial environments in the military $(19,20)$. To maintain battle fitness, military forces have well-developed medical services, which together with the cohesiveness of the organization, might protect against suicide. On the other hand, suicide risk could be increased in the military because of access to weaponry, access to marksmanship training, and possible self-selection of more aggressive individuals (21), aggression being a possible suicide risk factor, particularly in young male subjects $(22,23)$. However, some researchers have suggested that military populations, despite consisting mainly of young men, are no more aggressive than the general population (24), and others have suggested that military training or discipline may moderate impulsivity (21). Military authorities collect abundant demographic, occupational, and medical data, rendering military populations acceptable and rewarding settings in which to explore factors associated with suicide (particularly firearm suicide) in male subjects. We therefore hypothesized that suicide risk in the military, as in other 
TABLE 1. Studies of Suicide Rates in Military and Civilian Populations

\begin{tabular}{|c|c|c|c|c|c|c|}
\hline \multirow[b]{2}{*}{ Country and Author } & \multirow[b]{2}{*}{ Year } & \multirow[b]{2}{*}{ Period } & \multirow[b]{2}{*}{$\mathrm{N}$} & \multicolumn{2}{|c|}{ Suicide Rate (per 100,000 population) } & \multirow[b]{2}{*}{$\begin{array}{l}\text { Civilian Comparison } \\
\text { Population }\end{array}$} \\
\hline & & & & $\begin{array}{l}\text { Military } \\
\text { Personnel }\end{array}$ & Civilians & \\
\hline Canada: Wong et al. (5) & 2001 & 1990-1995 & 63 men & 12.2 & 26.2 & Men of comparable age \\
\hline \multicolumn{7}{|l|}{ Finland ${ }^{\mathrm{a}}$} \\
\hline Ponteva (6) & 1983 & 1977-1984 & 738 men & 13.6 & 46.8 & 20-24-year-old men \\
\hline Marttunen et al. (7) & 1997 & 1987-1988 & 7 men & & & \\
\hline \multicolumn{7}{|l|}{ France } \\
\hline Desjeux et al. (8) & 1998 & 1998 & 40 men & & & \\
\hline Galoisy-Guibal and Desjeux (9) & 2003 & 2001 & 49 men & 14 & & \\
\hline Italy: Mancinelli et al. (10) & 2003 & 1986-1998 & 122 men & $\begin{array}{l}2.0 \text { in } 1989 ; \\
1.1 \text { in } 1998\end{array}$ & $\begin{array}{l}7.3 \text { in } 1988 \\
11.5 \text { in } 1997\end{array}$ & 20-24-year-old men \\
\hline Norway: Hytten and Weisaeth (11) & 1989 & 1977-1984 & 331 men & 13.6 & 26.1 & 20-24-year-old men \\
\hline Poland: Florkowski et al. (12) & 2001 & 1989-1998 & 437 men & 17.3 & & \\
\hline Russia: Krupenik (2) & 1999 & 1998 & & 30.0 & $\begin{array}{l}42.1 \text { in } 1994 \\
39.7 \text { in } 2001^{b}\end{array}$ & \\
\hline Sweden ${ }^{\mathrm{a}}$ : Hytten and Weisaeth (11) & 1989 & 1977-1984 & 580 men & & 25.6 & 20-24-year-old men \\
\hline $\begin{array}{l}\text { Taiwan: Ming and Armed Forces } \\
\text { Peitou Hospital (13) }\end{array}$ & 2001 & 1999 & & 7.6 & 10.4 & \\
\hline $\begin{array}{l}\text { United Kingdom: } \\
\text { Fear and Williamson (14) }\end{array}$ & 2003 & 1984-2002 & 239 men & 11.0 & $\begin{array}{l}23.1 \text { for men ages } 20-24 \\
\text { years; } 25.6 \text { for men } \\
\text { ages } 25-29 \text { years }\end{array}$ & \\
\hline \multicolumn{7}{|l|}{ United States } \\
\hline Redmond and Walter (15) & 1985 & $\begin{array}{l}\text { 1982-1984 } \\
\text { inclusive }\end{array}$ & & 10.9 & & \\
\hline Sentell et al. (16) & 1997 & 1980-1992 & $\begin{array}{l}\text { 1,144 men; } \\
61 \text { women }\end{array}$ & $\begin{array}{l}13.2 \text { for men; } \\
6.0 \text { for women }\end{array}$ & $\begin{array}{l}23.8 \text { for men; } \\
6.5 \text { for women }\end{array}$ & \\
\hline Helmkamp (17) & 1995 & 1980-1992 & $\begin{array}{l}3,178 \text { men } \\
\text { and women }\end{array}$ & $\begin{array}{l}12.5 \text { for men; } \\
5.4 \text { for women }\end{array}$ & 23.79 for men & \\
\hline Powell et al. (18) & 2000 & 1980-1992 & & 12.5 & & \\
\hline
\end{tabular}

a Country with conscription into military forces.

${ }^{b}$ Estimate is based on publicly available statistics.

occupations such as health care and policing $(25,26)$, involves constitutional, environmental, and occupationspecific risk; that military service, like other occupations, influences suicide means (25-28); and that access to, familiarity with (29), and opportunity to use (30) the most lethal means constitute distinct components of that occupational risk.

\section{Method}

The Irish Defence Forces are a nonconscripted, ethnically homogenous military force tasked with maintaining internal security and international peacekeeping with the United Nations. Enlistment occurs from age 17 years, and women have been eligible for enlistment since 1981. Selection criteria include a medical history and examination. Causes of death for all regular-duty Army, Navy, Air Corps, and special forces personnel $(\mathrm{N}=732)$ (reserves excluded) from a dynamic cohort in service during the study period (1970-2002) were reviewed. During the study period, the period-averaged number of Irish Defence Forces personnel was 11,880 . Causes of death were determined by investigators (M.J.M. and J.P.T.) on the basis of examination of the proceedings of Courts of Inquiry convened under military law to investigate deaths, injuries, and discharges of weapons and examination of military personal/medical files, personal medical records, and civilian and military registers. For incidents that occurred outside of Ireland, proceedings of inquiries conducted by the United Nations were examined. The military files included civilian coroner/ inquest and autopsy reports, death certificates, military casualty reports, toxicology and forensic reports, and the accounts of eyewitnesses, partners, relatives, and military colleagues. The conservative standard of proof for suicide "caseness" determinations approximated "beyond reasonable doubt." "Caseness" interrater agreement achieved a kappa score of 0.95 . In the nested casecontrol study examining factors associated with suicide, cases were pair-matched for age and gender with contemporaneous (same study period) military comparison subjects randomly chosen from the group of personnel with nonsuicide deaths. Personnel with open-verdict deaths (e.g., deaths by drowning, train accidents, and single-vehicle road traffic accidents) were excluded.

Ethical approval for the study was received from the Mater Misericordiae Hospital Research Ethics Committee and the Irish Defence Forces Command Structure.

Chi-square tests and Fisher's exact tests (two-tailed) were used in the case-control bivariate analysis. The chi-square test for trend and the chi-square test for proportions were used to analyze ordered and unordered data, respectively. Paired or independent $t$ tests and Mann-Whitney tests were used to compare means. A binary logistic regression analysis model (31) was used to calculate odds ratios for suicide risk. Most analyses were performed with SPSS 11.0 for Windows (SPSS Inc., Chicago).

\section{Results}

\section{Cohort Study}

Table 1 summarizes studies of suicide among military personnel in various countries (5-18). Figure 1 and Figure 2 compare Irish military and civilian suicide rates and methods, respectively. Of the 732 deaths among enlisted Irish Defence Forces personnel in the period 1970-2002 inclusive, 63 (8.5\%) were suicides. Nonsuicidal drowning and road traffic accident deaths of military personnel during the study period numbered 38 (5.2\%) and 137 (18.7\%), respectively. We report period-averaged suicide rates per 100,000 population of 18.3 for male civilians in the $20-65$ - 
FIGURE 1. Suicide Rates Among Irish Defence Forces Personnel and Irish Civilians, 1970-2002

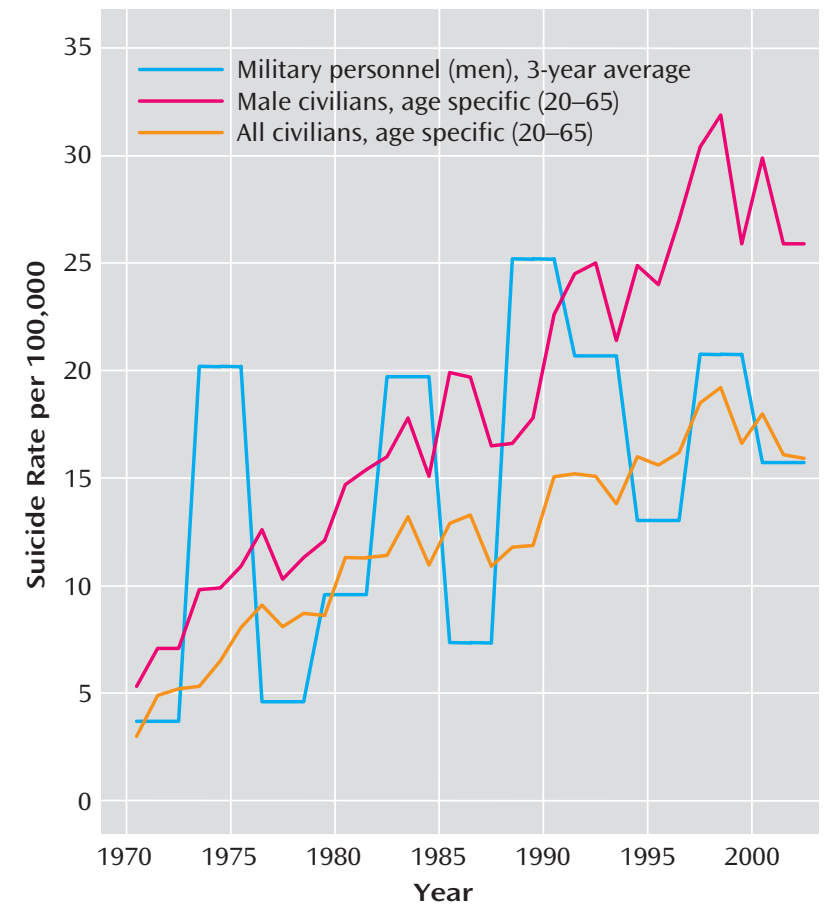

${ }^{\text {a }}$ Military personnel ranged in age from 17 to 65 years; civilians ranged in age from 20 to 65 years.

year age group and 15.3 for military personnel (17-65-year age group). Age-band rates (e.g., rates in the 20-24-year, 25-29-year, etc., age groups) were averaged for each year, totaled, and divided by the number of study years. All suicides in the military group involved male personnel, although the period-averaged number of female military personnel was 210 per year.

\section{Case-Control Studies}

Table 2 details results of the pair-matched case-control bivariate analysis of data for all personnel who died by suicide ( $\mathrm{N}=63)$ and the comparison subjects with nonsuicide deaths $(\mathrm{N}=63)$. The following characteristics were significantly associated with suicide: a psychiatric diagnosis (odds ratio $=11.9,95 \%$ confidence interval $[\mathrm{CI}]=3.3-42.6$ ), a past history of deliberate self-harm (odds ratio $=2.1,95 \%$ $\mathrm{CI}=1.8-2.6$ ), a recent psychiatric assessment (odds ratio= 2.2 , 95\% CI=1.8-2.6), being on morning duty (odds ratio= $3.3,95 \% \mathrm{CI}=1.2-9.7$ ), and being on a military site (odds ratio $=4.7,95 \% \mathrm{CI}=2.1-10.6)$.

Thirty-three (53\%) suicides were by firearm and most involved injuries to the head resulting from firing of a weapon placed in the mouth. Thirty-two (51\%) suicides occurred on a military site, and $23(37 \%)$ occurred while the person was on duty. However, almost all suicides on duty (except two drownings of naval personnel) were by firearm and occurred on a military site.
FIGURE 2. Suicide Methods Among Irish Defence Forces Personnel and Irish Civilians, 1970-2002

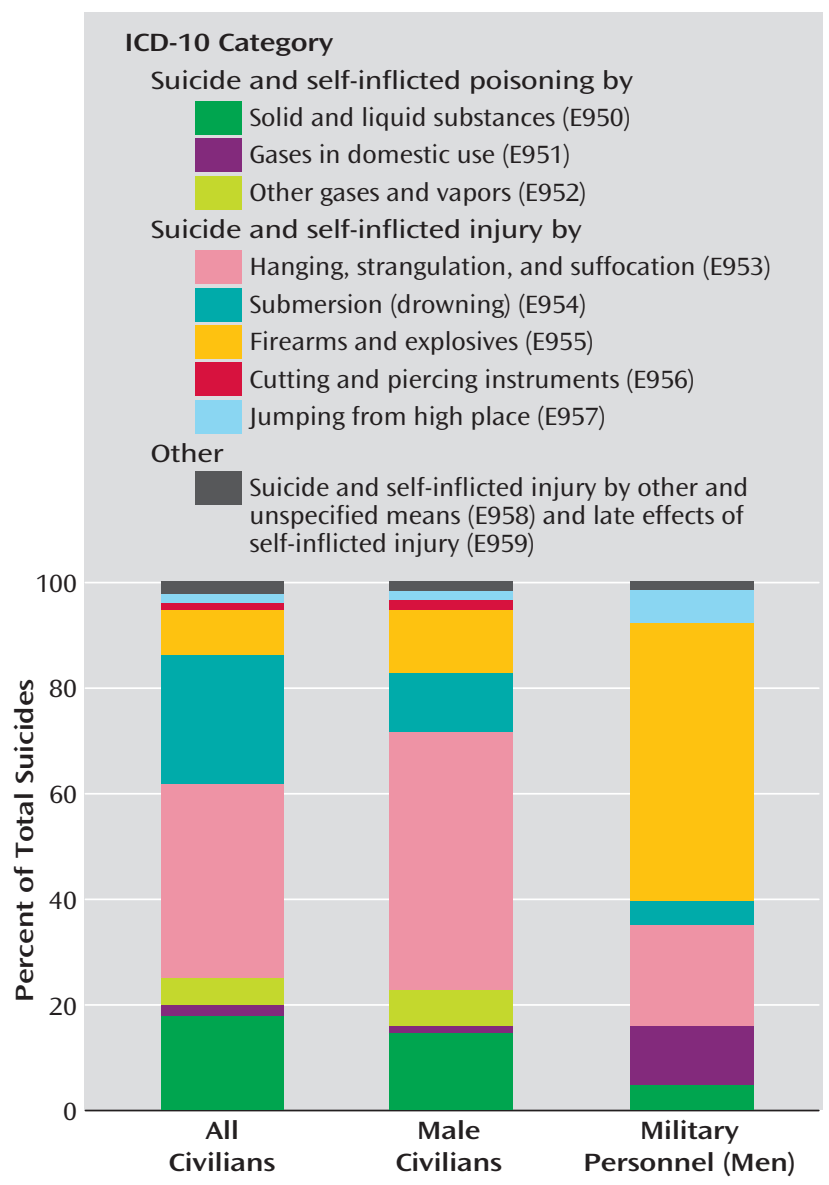

Bivariate analysis was used to compare the characteristics of the firearm suicide subgroup ( $\mathrm{N}=33$ ) and the comparison group with nonsuicide deaths $(\mathrm{N}=63)$. Table 3 lists variables with statistically significant differences. Death by firearm suicide was significantly associated with a psychiatric diagnosis (odds ratio $=10.8,95 \% \mathrm{CI}=2.7-42.9$ ), a past history of deliberate self-harm (odds ratio $=3.3,95 \%$ $\mathrm{CI}=2.4-4.5$ ), a recent psychiatric assessment (odds ratio= $3.3,95 \% \mathrm{CI}=2.4-4.5$ ), a recent medical downgrading (possible medical boarding) $(8.9,95 \% \mathrm{CI}=1.0-83.7)$, being on duty (odds ratio $=6.4,95 \% \mathrm{CI}=2.5-16.2$ ), being on morning duty (odds ratio $=9.1,95 \% \mathrm{CI}=2.8-30.1$ ), and being on a military site (odds ratio $=12.1,95 \% \mathrm{CI}=4.4-33.2$ ). Medical downgrading consisted of being reclassified to a lower level or grading of physical and mental fitness.

Of the 16 firearm suicides that occurred while the person was on duty, 11 (69\%) occurred within 4 hours of duty commencement, suggesting unequal distribution of suicide risk over time within periods of access (Figure 3). (Six suicides that occurred overseas were excluded from this analysis because access to firearms was constant in those settings.) Some firearm suicides that occurred on a military site while the person was off duty involved unauthorized access to weapons. 
TABLE 2. Demographic, Medical, and Occupational Factors and Circumstances of Death for Irish Defence Forces Personnel Who Died by Suicide and Comparison Defence Forces Personnel Who Died From Other Causes, 1970-2002

\begin{tabular}{|c|c|c|c|c|c|c|c|c|c|}
\hline \multirow[b]{4}{*}{ Characteristic } & \multirow{3}{*}{\multicolumn{3}{|c|}{$\begin{array}{c}\text { Personnel Who Died } \\
\text { by Suicide } \\
\text { With } \\
\text { Characteristic }\end{array}$}} & \multirow{3}{*}{\multicolumn{3}{|c|}{$\begin{array}{c}\text { Comparison Subjects } \\
\text { With } \\
\text { Characteristic }\end{array}$}} & \multirow{2}{*}{\multicolumn{3}{|c|}{ Analysis }} \\
\hline & & & & & & & & & \\
\hline & & & & & & & & Unadjusted & \\
\hline & $\mathrm{N}$ & $\mathrm{N}$ & $\%$ & $\mathrm{~N}$ & $\mathrm{~N}$ & $\%$ & $\mathrm{p}^{\mathrm{a}}$ & Odds Ratio & $95 \% \mathrm{Cl}$ \\
\hline \multicolumn{10}{|l|}{ Demographic characteristics } \\
\hline Single & 63 & 35 & 56 & 63 & 35 & 56 & 1.00 & 1.0 & $0.5-2.0$ \\
\hline Parent & 60 & 24 & 40 & 63 & 27 & 43 & 0.75 & 0.9 & $0.4-1.8$ \\
\hline Age of youngest child (years) & 21 & & & 27 & & & 0.20 & 0.5 & $0.14-1.5$ \\
\hline$\leq 4$ & & 11 & 52 & & 19 & 70 & & & \\
\hline$>4$ & & 10 & 48 & & 8 & 30 & & & \\
\hline Number of children & 23 & & & 26 & & & 0.10 & 3.0 & $0.8-11.3$ \\
\hline$\leq 3$ & & 19 & 83 & & 16 & 62 & & & \\
\hline$>3$ & & 4 & 18 & & 10 & 39 & & & \\
\hline Urban origin & 63 & 51 & 81 & 63 & 51 & 81 & 1.00 & 1.0 & $0.4-2.4$ \\
\hline Mandatory education onlyb & 17 & 61 & 28 & 26 & 63 & 41 & 0.12 & 0.6 & $0.3-1.2$ \\
\hline Employed before enlistment & 63 & 47 & 75 & 63 & 54 & 86 & 0.12 & 0.5 & $0.2-1.2$ \\
\hline \multicolumn{10}{|l|}{ Clinical characteristics } \\
\hline Psychiatric diagnosis ever recorded or present at death & 59 & 23 & 39 & 59 & 3 & 5 & 0.001 & 11.9 & $3.3-42.6$ \\
\hline Military psychiatric evaluation ever & 58 & 12 & 21 & 59 & 2 & 3 & 0.004 & 7.4 & $1.6-35.0$ \\
\hline Psychiatric assessment within the last 6 months & 58 & 8 & 12 & 59 & 0 & 0 & 0.003 & 2.2 & $1.8-2.6$ \\
\hline Alcohol use present at death & 63 & 15 & 24 & 63 & 9 & 14 & 0.17 & 1.9 & $0.8-4.7$ \\
\hline Past deliberate self-harm documented & 58 & 6 & 10 & 59 & 0 & 0 & $<0.02^{\mathrm{C}}$ & 2.1 & $1.8-2.6$ \\
\hline Medical downgrading within the last 3 months & 58 & 6 & 10 & 59 & 1 & 2 & $0.06^{\mathrm{C}}$ & 6.7 & $0.8-57.4$ \\
\hline Medical assessment within the last 3 months & 58 & 35 & 60 & 59 & 26 & 44 & 0.08 & 1.9 & $0.9-4.0$ \\
\hline \multicolumn{10}{|l|}{ Occupational characteristics } \\
\hline Died on military site & 63 & 32 & 51 & 61 & 11 & 18 & 0.001 & 4.7 & $2.1-10.6$ \\
\hline Died in the morning & 55 & 40 & 73 & 58 & 27 & 47 & 0.005 & 3.1 & $1.4-6.7$ \\
\hline Died on morning duty ${ }^{d}$ & 44 & 18 & 41 & 35 & 6 & 17 & $<0.03$ & 3.3 & $1.2-9.7$ \\
\hline Disciplinary action ever recorded & 61 & 30 & 48 & 63 & 42 & 66 & $<0.05$ & 0.5 & $0.2-1.0$ \\
\hline Died on a weekday & 62 & 37 & 60 & 63 & 31 & 49 & 0.24 & 1.5 & $0.8-3.1$ \\
\hline Died while on duty & 63 & 23 & 37 & 63 & 15 & 24 & 0.12 & 1.8 & $0.9-4.0$ \\
\hline
\end{tabular}

Paired t tests comparing the mean numbers of children and ages of the youngest children of the subjects who died by suicide and the comparison subjects were not significant.

Bivariate analysis demonstrated no significant increase in risk of death by suicide, compared to other causes, related to rank or service corps, but a chi-square test for trend of the relative contributions to the number of suicides by rank was highly significant (trend $\chi^{2}=73.1, \mathrm{df}=2$, $\mathrm{p}<0.001$ ), suggesting that suicides of privates (lowest noncommissioned rank) disproportionately contributed to the total number of suicides. However, a chi-square test of proportions (unordered data) examining relative contribution to the number of suicides by service corps was not significant $\left(\chi^{2}=0.91, \mathrm{df}=2, \mathrm{p}>0.05\right)$. Drowning accounted for two of the five suicides among naval personnel.

During the study period, $10 \%(\mathrm{~N}=6)$ of the deaths overseas (where troops are always armed and duties often solitary) were suicides, yet the mean number of overseas trips was not significantly different between the personnel who died by suicide and the comparison subjects $(\mathrm{z}=-1.71$, $\mathrm{p}>0.05$, Mann-Whitney).

Fifty-one percent $(\mathrm{N}=32)$ of the suicides occurred in men age $17-25$ years, and $30 \%(\mathrm{~N}=19)$ occurred in men age
25-34 years. All firearm suicides, including those involving military weapons $(\mathrm{N}=25)$, occurred when personnel were deliberately alone, thus providing opportunity. Suicidal intent was indicated by 12 men who died by suicide (19\%), most of whom used a firearm.

Prodromal signs, e.g., restlessness, isolation, or low mood, were retrospectively noted by colleagues in 24 (38\%) cases. Thirty-six (57\%) persons who died by suicide had significant life events (mainly relationship and financial difficulties) noted in records of subsequent inquiries.

\section{Logistic Regression}

Factors suggested by the bivariate analyses and the literature and factors that were clinically or occupationally associated with suicide were entered into a binary logistic regression analysis model (31) examining the 33 firearm suicides of particular relevance to military authorities. Precedent exists for attempting to establish factors influencing choice of suicide method (32), particularly in persons who die by firearm suicide (33) and those who survive attempted suicide by firearm (34). Deliberate self-harm and psychiatric illness, which were the only nonindependent variables, were combined into one variable that designated persons with either a psychiatric diagnosis or a past history of deliberate self-harm. The model identified three vari- 
TABLE 3. Demographic, Medical, and Occupational Characteristics of Irish Defence Forces Personnel Who Died by Firearm Suicide $(\mathrm{N}=33)$ and Comparison Defence Forces Personnel Who Died From Other Causes $(\mathrm{N}=63), 1970-2002^{\mathrm{a}}$

\begin{tabular}{|c|c|c|c|c|c|c|c|c|c|}
\hline \multirow[b]{4}{*}{ Characteristic } & \multirow{3}{*}{\multicolumn{3}{|c|}{$\begin{array}{c}\text { Personnel Who Died } \\
\text { by Firearm Suicide } \\
\text { With } \\
\text { Characteristic }\end{array}$}} & \multicolumn{3}{|c|}{ Comparison Subjects } & \multirow{2}{*}{\multicolumn{3}{|c|}{ Analysis }} \\
\hline & & & & \multirow[b]{3}{*}{$\mathrm{N}$} & \multirow{2}{*}{\multicolumn{2}{|c|}{$\begin{array}{c}\text { With } \\
\text { Characteristic }\end{array}$}} & & & \\
\hline & & & & & & & \multirow[b]{2}{*}{$\mathrm{p}^{\mathrm{b}}$} & \multirow{2}{*}{$\begin{array}{l}\text { Unadjusted } \\
\text { Odds Ratio }\end{array}$} & \multirow[b]{2}{*}{$95 \% \mathrm{Cl}$} \\
\hline & $\mathrm{N}$ & $\mathrm{N}$ & $\%$ & & $\mathrm{~N}$ & $\%$ & & & \\
\hline Died on military site & 33 & 24 & 72 & 61 & 11 & 18 & 0.001 & 12.1 & $4.4-33.2$ \\
\hline Psychiatric diagnosis ever recorded or present at death & 30 & 11 & 37 & 59 & 3 & 5 & 0.001 & 10.8 & $2.7-42.9$ \\
\hline Medical downgrading within the past 3 months & 30 & 4 & 13 & 59 & 1 & 2 & $<0.05^{\mathrm{c}}$ & 8.9 & $1.0-83.7$ \\
\hline Died during morning duty & 26 & 17 & 66 & 35 & 6 & 17 & 0.001 & 9.1 & $2.8-30.1$ \\
\hline Died on duty & 33 & 22 & 67 & 63 & 15 & 24 & 0.001 & 6.4 & $2.5-16.2$ \\
\hline Military psychiatric evaluation ever & 30 & 5 & 17 & 59 & 2 & 3 & $<0.05^{\mathrm{C}}$ & 5.7 & $1.0-31.4$ \\
\hline Past deliberate self-harm documented & 30 & 4 & 13 & 59 & 0 & 0 & $<0.02^{\mathrm{C}}$ & 3.3 & $2.4-4.5$ \\
\hline Psychiatric assessment within the past 3 months & 30 & 4 & 13 & 59 & 0 & 0 & $<0.02^{\mathrm{c}}$ & 3.3 & $2.4-4.5$ \\
\hline Died in the morning & 31 & 22 & 71 & 58 & 27 & 47 & $<0.03$ & 2.8 & $1.1-7.1$ \\
\hline Indicated suicidal intent before death & 33 & 10 & 30 & 63 & 0 & 0 & 0.001 & 3.74 & $2.6-5.3$ \\
\hline
\end{tabular}

a Only statistically significant differences between groups are presented.

${ }^{\mathrm{b}}$ Chi-square or Fisher's exact tests (for analyses in which the expected count was $<5$ in $20 \%$ of cells).

' Fisher's exact test.

FIGURE 3. Distribution of Firearm Suicides Among On-Duty Irish Defence Forces Personnel $(\mathrm{N}=16)$, by Time Period ${ }^{\mathrm{a}}$

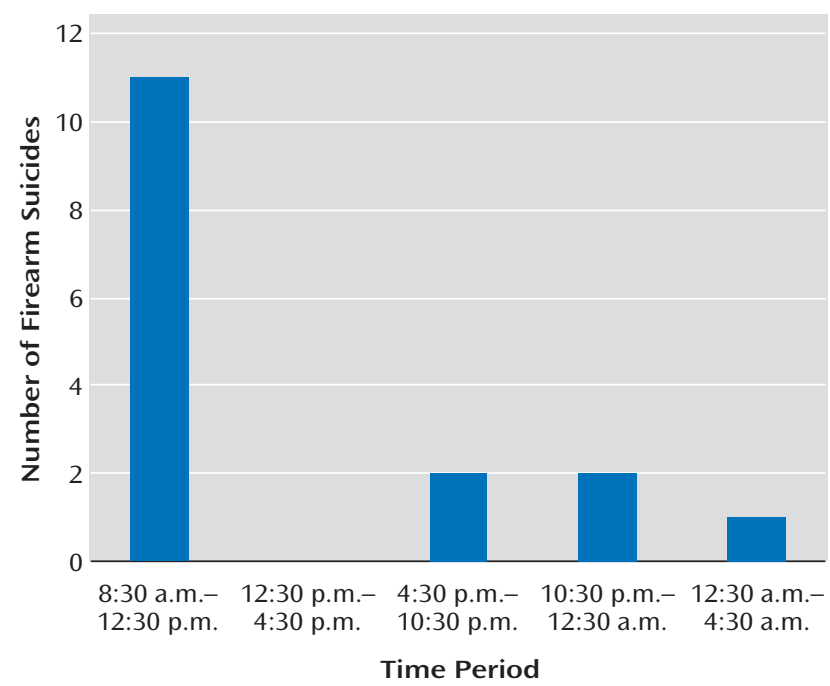

${ }^{\text {a }}$ Access to weapons occurred with commencement of duty at 8:30 a.m.

ables that accounted for $84.2 \%$ of the variation in the data and $83.3 \%$ of the firearm suicides $\left(\chi^{2}=1.0, \mathrm{df}=2, \mathrm{p}<0.001\right)$ : psychiatric illness or a history of deliberate self-harm (odds ratio $=0.00,95 \% \mathrm{CI}=0.00-8.3 \times 10^{33}$ ), performing morning duty (odds ratio $=12.6,95 \% \mathrm{CI}=2.78-57.27$ ), and a recent medical downgrading (odds ratio $=27766.31,95 \%$ $\left.\mathrm{CI}=0.00-1.17 \times 10^{58}\right)$. Because suicide is a rare event, the number of study subjects is unavoidably limited; this limitation explains the large confidence intervals and creates the need for cautious interpretation.

\section{Discussion}

\section{Cohort Study}

Notwithstanding the unreliability of Irish civilian suicide rates (35) and easier identification of suicide among military personnel because of mandatory military inquiries, we report a period-averaged age-adjusted suicide rate among male military personnel that is lower than that of male civilians but higher than that of all civilians. Standardized mortality ratios were not calculated because of the unreliability of civilian data and incompatibilities in the organization of civilian and military data over the study period. Only $44 \%(\mathrm{~N}=28)$ of suicides were so determined by military inquiries, "death due to accidental discharge of weapon" being the commonest conclusion. The lower rate of firearm suicides (53\%) among all suicides among Irish military personnel, compared to the rates for U.S. military personnel (61\%) (17) and for New York City (92\%) (26) and German (71\%) (36) police personnel, may reflect tight control of weapon/ammunition access in a military force that is ever conscious of the risk that weapons/ammunition could fall into terrorists' hands. The smaller proportion of suicidal drownings among military personnel, compared to civilians, may be explained by access to firearms among military personnel. Firearms have been identified as the most lethal means of suicide (37, 38 ), with suicidal acts involving firearms resulting in death more often than acts involving the second most lethal means, suffocation (37).

\section{Case-Control Studies}

Private rank was significantly overrepresented among the personnel who died by suicide, compared to other ranks (e.g., noncommissioned officers and officers), and this result was similar to international findings $(5,12,17)$. Possibly because they had less access to firearms (39), naval personnel who died by suicide more often chose an accessible ubiquitous means, suicidal drowning.

The finding that suicidal intent was articulated by several personnel who eventually died by suicide $(\mathrm{N}=12)$ requires cautious extrapolation. Reports of suicidal intent were probably more reliably elicited in inquiries into firearm suicides, as deaths following expression of suicidal in- 
tent tended to occur on military installations and while the person was on duty $(\mathrm{N}=8)$. These findings may have implications for psychiatric referral/assessment or for a "buddy system," as deployed in many U.S. units (40), to facilitate earlier detection and intervention.

Evidence-based guidelines in the assessment of suicide risk in weapon-bearing personnel might aid military psychiatrists. Our bivariate analysis, echoing data from other studies, highlights the contribution to military suicide of psychiatric indicators and psychiatric illness $(7,41,42)$, particularly alcohol misuse problems (43). The temporal association between suicide and prodromal signs of mental illness (44), relationship difficulties (mostly marital/ sexual), civilian legal actions $(5,12,45)$, feared medical boarding (discharge) (46), and recent reprimand or punishment were also important. In the Irish forces, as in many others, personnel are referred to psychiatrists by medical officers, not by commanding officers. In our study, personnel with psychiatric diagnoses who died by suicide included 10 subjects with affective disorders (43\% of those with psychiatric diagnoses), seven with alcohol misuse $(30 \%)$, one with anxiety $(4.3 \%)$, and only two with psychotic spectrum disorders (8.7\%). A study of occupational dysfunction due to mental disorder in the U.S. military in the 1990s revealed that by 1995 mental disorders had become the second leading cause of hospitalization (47). The most common primary diagnoses over the study period were substance misuse, adjustment disorders, affective disorders, and personality disorders. Nine percent of outpatient visits were attributed to mental disorder. Hospitalization or outpatient care for mental disorder was highly correlated with military attrition. Reduced suicide rates associated with a suicide intervention program in the U.S. Air Force were recently reported (48). The program prioritized early prevention, early intervention, improved treatment, and risk detection. Fundamental to the approach was the reduction of stigma in order to encourage help-seeking behavior. Military personnel may be reluctant to seek help, because concealment of psychiatric illness at enlistment can result in subsequent administrative discharge (24). In many forces, attempted suicide and deliberate self-harm contravene military law (49). Psychiatrists may be perceived as those who impose occupational restrictions, including perhaps denying access to weaponry (24), thus contributing to a "professional humiliation" factor. In our study, $60 \%$ of the subjects who died by suicide had consulted a doctor in the 3 months before death. Incorporation of mental health screening in annual and pre-overseas medical examinations and in all consultations might therefore help foster healthier personnel.

Evidence suggests that reduced access to firearms and other methods lower civilian suicide rates (50-52). Firearms are a necessary military occupational hazard, yet only a few studies of the efficacy of military suicide reduction strategies exist $(48,53-55)$. Safer workplaces (military sites) should allow only minimal authorized and neces- sary access to and reduced opportunity to use such occupational hazards as weaponry and ammunition and should prevent personnel from being alone with armed weaponry. Distinctly realizable targets in any risk reduction strategy include reducing the extent of weapon bearing (reducing the number of personnel who carry firearms or the frequency of armed duties), supervision of personnel who bear weapons, and consideration of the weapon bearer's profile (age, history of psychiatric illness and past self-harm), together with the reduction of occupationspecific stresses. Military authorities should ensure adherence on all installations to the separation of ammunition and weaponry. Stringent protocols should be followed regarding who may have access to either ammunition or weapons or both and regarding the supervision of such personnel. Ammunition accounting protocols and possible use of metal detectors could minimize stockpiling of ammunition or weapons.

The uneven suicide risk distribution over time within periods of weapon access (shown in Figure 3) among military personnel who largely had advance notice of their duty schedule suggests premeditation in anticipation of such access and parallels findings in civilian groups. For example, follow-up of 238,292 U.S. handgun purchasers found that handgun purchase was associated with a substantial increase in firearm suicide risk within a week of the purchase (56). Suicide was the leading cause of death (24.5\% of all deaths) in this group in the year after handgun purchase.

Firearm suicide was associated with younger age in a large U.S. civilian study that found that firearm suicide was substantially more likely in persons younger than age 21 and in men (33). Even though only $14 \%$ of suicides among male civilians in our study setting occurred in the 20-25-year age group, our finding that a large proportion (up to $50 \%$ ) of suicides among military personnel occurred in the first 5 years of military service or in the early service period (under age 24 years) is not unique (10-14, 17). Consequently educational and risk reduction strategies $(55,57,58)$ should focus on this postenlistment period. Armed duties may represent less risk for more mature soldiers, who are well known to commanding officers, compared to new recruits or young soldiers.

Opportunity to use a lethal means (e.g., solitary armed duty), as distinct from access to lethal means, is an additional important variable. Minimizing suicide risk in weapon bearers could be achieved by reducing unsupervised access to armed weapons. Eliminating solitary armed duties or performing these duties under camera surveillance if they cannot be eliminated might reduce the opportunity for suicide, as evidenced in other settings (59).

We failed to replicate the importance of suicide risk factors suggested by earlier authors, including preenlistment criminality, absent-without-official-leave (AWOL) frequency, history of disciplinary offenses (41), and greater specialty-related firearm familiarity and access, as ob- 
served in U.S. forces (29) among U.S. Marines, small arms technicians, and Army infantry soldiers. However, in this study, familiarity with firearms could underpin the higher proportion of firearm suicides among the suicides of military personnel that took place on a military installation, compared to the rate of firearm suicides among suicides in the civilian male population and among military personnel $(\mathrm{N}=8)$ who did not use military weaponry and who died off a military site.

A lower incidence of suicides among military personnel overseas might be expected because of the additional health screening of these troops. Nevertheless, peacekeepers face particular stresses, including separation from family/partners, sporadic combat situations in hostile and unfamiliar territories, constant availability for duty, alcohol use, and isolation (60-62). Our analysis revealed no statistically significant differences between the military personnel who died by suicide and the comparison subjects for any measure of overseas or border duty, perhaps replicating studies in peacekeepers (5) and Vietnam draftees $(41,63)$, despite differences in combat intensity.

\section{Limitations}

Although record-based data were used in this study, the demographic, medical, and most occupational data are both objective and uncontroversial, thus reducing bias. Some occupational variables, e.g., disciplinary action or AWOL frequency, may vary in application and recording in different military units. Not all data were available for each case; for example, it was not possible to collate all toxicology data or discern whether toxicology screens were performed. Strict "caseness" criteria may have underestimated the suicide rate. Inconsistencies in reporting for different overseas mission types and theaters hindered objective determination of the severity of combat exposure. As in all military forces, weapon access is neither universal nor constant, yet it was not possible to calculate a suicide rate corrected for the extent of weapon bearing. Because of the small numbers of suicides in this study group, particularly in some of the service corps, and the absence of suicide among female military personnel, caution is warranted in extrapolation of the data.

\section{Conclusions}

Suicide among military personnel is an informative model with which to explore workplace suicide and occupation-specific suicide risk factors seen in many professions. Our findings suggest that significant factors in workplace suicide include opportunity to use lethal means in occupational settings and the uneven distribution of suicide risk within periods of access to lethal means.

Military authorities could create safer workplaces by reducing the extent of weapon bearing, unnecessary and unauthorized access to weapons, and opportunity to use lethal means for suicide. Attending to the weapon bearer's profile, including age and medical and psychiatric indicators, and minimizing the influence of occupation-specific stress could reduce suicide risk. Our findings thus have implications for military health services, military law, enlistment policies, and military inquiries.

Occupation-specific studies of suicide and evidencebased, occupation-specific risk reduction strategies are required in the military and other occupations where access to lethal means is a factor in suicide risk. Suicide reduction strategies centered on access and opportunity (48) have applicability in other at-risk professions and may be more easily implemented in certain workplaces (e.g., military sites, hospitals, police departments), perhaps because of the cohesiveness of those settings and the availability of health care in those settings $(12,27,48)$. Research could explore the validity for the workplace of the "substitution hypothesis," which suggests that although certain methodspecific suicide rates may be amenable to reduction, compensatory increases may occur in others (64). However, greater use of less lethal means in suicide attempts might reduce lethality and rates of death by suicide. Research on the effects of suicide reduction strategies in various professions and the applicability of these strategies to professions at higher risk is required (48).

Received March 9, 2004; revisions received June 14 and Aug. 13, 2004; accepted Sept. 9, 2004. From the Department of Psychiatry and Mental Health Research, St. Vincent's University Hospital and University College Dublin; St. Bricin's Military Hospital, Dublin; the Departments of Legal Medicine and of Public Health and Epidemiology, University College Dublin; and County Kildare Coroner's Office, Naas, County Kildare, Ireland. Address correspondence and reprint requests to Dr. Mahon, Department of Psychiatry and Mental Health Research, St. Vincent's University Hospital and University College Dublin, Elm Park, Dublin 4, Ireland; docmartins@gmail.com (e-mail).

Supported by the Irish Defence Forces, the Department of Defence, and the National Suicide Review Group.

The authors thank James McGowan, Gail Birkbeck, J.M. Rothberg, and Elspeth Cameron Ritchie for their review of drafts.

\section{References}

1. Ritchie EC, Keppler WC, Rothberg JM: Suicidal admissions in the United States military. Mil Med 2003; 168:177-181

2. Krupenik N: Russian Army's suicide toll $22.7 \%$ of all casualties. Itar-Tass, April 20, 1999

3. Spooner $\mathrm{MH}$ : Suicide claiming more British Falkland veterans than fighting did. CMAJ 2002; 166:1453

4. Nelson R: Suicide rates rise among soldiers in Iraq. Lancet 2004; 363:300

5. Wong A, Escobar M, Lesage A, Loyer M, Vanier C, Sakinofsky I: Are UN peacekeepers at risk for suicide? Suicide Life Threat Behav 2001; 31:103-112

6. Ponteva M: Aspects of the suicides of conscripts in the Finnish Defence Forces. Psychiatr Fenn Suppl 1983; 2:97-103

7. Marttunen M, Henriksson M, Pelkonen S: Suicide among military conscripts in Finland: a psychological autopsy study. Mil Med 1997; 162:14-19

8. Desjeux G, Lemardeley P, Vallet D, Pascal B, Labarere J: Suicide and attempted suicide in the armed forces in 1998. Encephale 2001; 27:320-324 
9. Galoisy-Guibal L, Desjeux G: Resultats de la surveillance épidémiologique des conduits suicidaires (CS) dans les armées en 2001. Bulletin Epidémioligique des Armées 2003; 4:2-4

10. Mancinelli I, Lazanio S, Comparelli A, Ceciarelli L, Di Marzo S, Pompili M, Girardi P, Tatarelli R: Suicide in the Italian military environment (1986-1998). Mil Med 2003; 168:146-152

11. Hytten $\mathrm{K}$, Weisaeth $\mathrm{L}$ : Suicide among soldiers and young men in the Nordic countries 1977-1984. Acta Psychiatr Scand 1989; 79:224-228

12. Florkowski A, Gruszczynski W, Wawrzyniak Z: Evaluation of psychopathological factors and origins of suicides committed by soldiers, 1989 to 1998. Mil Med 2001; 166:44-47

13. Suicide rate in military relatively low: survey. Taiwan Headlines, June 13, 2001. http://www.taiwanheadlines.gov.tw/ 20010613/20010613s6.html

14. Fear NT, Williamson S: Suicide and open verdict deaths among males in the UK regular armed forces: comparison with the UK civilian population and the US military. London, Defence Analytic Services Agency, July 14, 2003. http://www.dasa.mod.uk/ reports/suicide.pdf

15. Redmond R, Walter LJ: Suicide Among Active Duty Military Personnel. Washington, DC, Office of the Secretary of Defense for Health Affairs, 1985

16. Sentell JW, Lacroix M, Sentell JV, Finstuen K: Predictive patterns of suicidal behavior: the United States armed services versus the civilian population. Mil Med 1997; 162:168-171

17. Helmkamp JC: Suicides in the military: 1980-1992. Mil Med 1995; 160:45-51

18. Powell KE, Fingerhut LA, Branche CM, Perotta DM: Deaths due to injury in the military. Am J Prev Med 2000; 18(3 suppl):26-32

19. Carpenter LM: Some observations on the healthy worker effect. Br J Indust Med 1987; 44:289-291

20. Rothberg JM, Bartone PT, Holloway HC, Marlowe DH: Life and death in the US Army: in corpore sano. JAMA 1990; 264:22412244

21. Turner MA, Neal LA: Military forensic psychiatry (editorial). Br J Psychiatry 2003; 183:10-11

22. Brent DA, Bridge J, Johnson BA, Connolly J: Suicidal behavior runs in families: a controlled family study of adolescent suicide victims. Arch Gen Psychiatry 1996; 53:1145-1152

23. Brent DA, Mann JJ: Family genetic studies, suicide, and suicidal behavior. Am J Med Genet C Semin Med Genet 2005; 133:13-24

24. McPherson J: Forensic aspects of the armed forces, in Principles and Practice of Forensic Psychiatry. Edited by Bluglass R, Bowden P. London, Churchill Livingstone, 1990, pp 13-96

25. Hawton K, Clements A, Simkin S, Malmberg A: Doctors who kill themselves: a study of the methods used for suicide. QJM 2000; 93:351-357

26. Marzuk PM, Nock MK, Leon AC, Portera L, Tardiff K: Suicide among New York City police officers, 1977-1996. Am J Psychiatry 2002; 159:2069-2071

27. Conroy C: Suicide in the workplace: incidence, victim characteristics, and external cause of death. J Occup Med 1989; 31: 847-850

28. Koskinen O, Pukkila K, Hakko H, Tiihonen J, Vaisanen E, Sarkioja T, Rasanen P: Is occupation relevant in suicide? J Affect Disord 2002; 70:197-203

29. Helmkamp JC: Occupation and suicide among males in the US armed forces. Ann Epidemiol 1996; 6:83-88

30. Malone KM: Psychobiology of suicidal behaviour in major depression (MD thesis). Dublin, Ireland, University College, 1994, fig $2.1, p 20$

31. Hosmer DW, Lemeshow S: Applied Logistic Regression. New York, John Wiley \& Sons, 1989

32. De Leo D, Evans R, Neulinger K: Hanging, firearm, and non-domestic gas suicides among males: a comparative study. Aust NZ J Psychiatry 2002; 36:183-189
33. Sorenson SB, Berk RA: Young guns: an empirical study of persons who use a firearm in a suicide or a homicide. Inj Prev 1999; 5:280-283

34. de Moore GM, Robertson AR: Suicide attempts by firearms and by leaping from heights: a comparative study of survivors. Am J Psychiatry 1999; 156:1425-1431

35. McCarthy PD, Walsh D: Suicide in Dublin: I. the under-reporting of suicide and the consequences for national statistics. Br J Psychiatry 1975; 126:301-308

36. Schmidtke A, Fricke S, Lester D: Suicide among German federal and state police officers. Psychol Rep 1999; 84:157-166

37. Shenassa ED, Catlin SN, Buka SL: Lethality of firearms relative to other suicide methods: a population based study. J Epidemiol Community Health 2003; 57:120-124

38. Stark C, Matthewson F, O'Neill N, Oates K, Hay A: Suicide in the Highlands of Scotland. Health Bull (Edinb) 2002; 60:27-32

39. Hourani L, Warrack G, Coben P: A demographic analysis of suicide among US Navy personnel. Suicide Life Threat Behav 1999; 29:365-375

40. Gaines T, Skaer WK: A suicide prevention program for basic military trainees. Mil Med 1979; 144:623-624

41. O'Toole BI, Cantor C, Suicide risk factors among Australian Vietnam era draftees. Suicide Life Threat Behav 1995; 25: 475-488

42. Schuckit MA, Gunderson EK: Suicide in the naval service. Am J Psychiatry 1974; 131:1328-1331

43. Rossow I, Amundsen A: Alcohol abuse and suicide: a 40-year prospective study of Norwegian conscripts. Addiction 1995; 90:685-691

44. Mehlum L: Prodromal signs and precipitating factors in attempted suicide. Mil Med 1992; 157:574-577

45. Rothberg JM, Jones FD: Suicide in the US Army: epidemiological and periodic aspects. Suicide Life Threat Behav 1987; 17: 119-132

46. Fragala MR, McCaughey BG: Suicide following medical/physical evaluation boards: a complication unique to military psychiatry. Mil Med 1991; 156:206-209

47. Hoge CW, Lesikar SE, Guevara R, Lange J, Brundage JF, Engel CC, Messer SC, Orman DT: Mental disorders among US military personnel in the 1990s: association with high levels of health care utilization and early military attrition. Am J Psychiatry 2002; 159:1576-1583

48. Knox KL, Litts DA, Talcott WG, Feig JC, Caine ED: Risk of suicide and related adverse outcomes after exposure to a suicide prevention programme in the US Air Force: cohort study. BMJ 2003; 327:1376-1378

49. Ritchie EC: Malingering and the United States military, in Principles and Practice of Military Forensic Psychiatry. Edited by Lande RG, Armitage DT. Springfield, III, Charles C Thomas, 1997, pp 122-133

50. Lewis G, Hawton, K, Jones P: Strategies for preventing suicide. Br J Psychiatry 1997; 171:351-354

51. Marzuk PM, Leon AC, Tardiff K, Morgan EB, Stajic M, Mann JJ: The effect of access to lethal weapons of injury on suicide rates. Arch Gen Psychiatry 1992; 49:451-458

52. Kellermann AL, Rivara FP, Somes G, Reay DT, Francisco J, Banton JG, Prodzinski J, Fligner C, Hackman BB: Suicide in the home in relation to gun ownership. N Engl J Med 1992; 327:467-472

53. Menenberg SR, Munson DA: Suicide prevention: a case study analysis. Navy Medicine, July-Aug 1992, pp 36-38

54. Russell HE, Conroy RW, Werner JJ: A study of suicidal behavior in the military setting. Mil Med 1971; 136:549-552

55. Mehlum L, Schwebs R: Suicide prevention in the military: recent experiences from the Norwegian armed forces. Int Rev Armed Forces Med Services 2001; 74:71-74 


\section{SUICIDE IN MILITARY PERSONNEL}

56. Wintemute GJ, Parham CA, Beaumont JJ, Wright M, Drake C: Mortality among recent purchasers of handguns. N Engl J Med 1999; 341:1583-1589

57. James LC, Kowalski TJ: Suicide in an army infantry division: a multidisciplinary program. Mil Med 1996; 161:97-101

58. Suicide prevention among active duty Air Force personnelUnited States, 1990-1999. MMWR Morb Mortal Wkly Rep 1999; 48:1053-1057

59. Smialek JE, Spitz WU: Death behind bars. JAMA 1978; 240: 2563-2564

60. Carlstrom A, Lundin T, Otto U: Mental adjustment of Swedish UN soldiers in South Lebanon in 1988. Stress Med 1990; 6:305-310
61. Hansen-Schwartz J, Jessen G, Andersen K, Jorgensen HO: Suicide after deployment in UN peacekeeping missions-a Danish pilot study. Crisis 2002; 23:55-58

62. Rothberg JM: Stress and suicide in the US Army: effects of relocation on service members' mental health. Armed Forces Soc $1991 ; 17: 449-458$

63. Adena MA, Cobbin DM, Fett MJ, Forcier L, Hudson HM, Long AA, Nairn JR, O'Toole BI: Mortality among Vietnam veterans compared with non-veterans and the Australian population. Med J Aust 1985; 143:541-544

64. Rich CL, Young JG, Fowler RC, Wagner J, Black NA: Guns and suicide: possible effects of some specific legislation. Am J Psychiatry 1990; 147:342-346 